ISSN 0511-5728

The West Indian Journal of Engineering

Vol.44, No.1, July 2021, pp.11-17

\title{
Barbados towards 100\% Renewable Energy: Case Scenarios for 2030 National Energy Target Plans
}

\author{
Sheldon Marshall a and Randy Koon Koon ${ }^{\text {b, }}{ }^{\text {a }}$ \\ Department of Physics, University of the West Indies, Mona Campus, Jamaica, West Indies; \\ aEmail: sheldon.marshall@mymona.uwi.edu \\ bEmail: randy.koonkoon@uwimona.edu.jm \\ ${ }^{\Psi}$ Corresponding Author
}

(Received 27 September 2020; Revised 18 January 2021; Accepted 10 June 2021)

\begin{abstract}
The integration of renewable energy ( $R E$ ) into the overall energy mix of Caribbean nations has been increasing in recent times. The volatile nature of the carbon-based industry through fluctuations in prices of fossil fuel basedproducts renders it necessary to promote an aggressive energy profile transition to renewable energy, as this is crucial to energy security in these vulnerable Small Island Developing States (SIDS). The nation of Barbados has notably understood this reality and, as such, its government has endorsed the approach of 100\% RE implementation by 2030. This paper explores three distinctive annual growth rate (AGR) scenarios to assess the impact on the expected power generation, economic and environmental parameters through the period of 2019-2030. Notable findings at a high case scenario for 2030 (at an AGR of 3\%) projects a power generation of 1.343 Tera-watts-hour (TWh), which will displace 790,500 barrels of oil equivalent (boe), resulting in an abatement of approximately 0.95 million tons of carbon dioxide into the atmosphere.
\end{abstract}

Keywords: Barbados, annual growth rate, renewable energy, carbon neutral

\section{Introduction}

\subsection{Brief history of Barbados}

Barbados is a Caribbean island country situated in the Lesser Antilles of the West Indies and sits about $100 \mathrm{~km}$ East of the Windward Islands, the most easterly of the Caribbean islands. It is located at $13.1939^{\circ} \mathrm{N}, 59.5432^{\circ}$ $\mathrm{W}$. The country is 34 kilometers in length and 23 kilometers in width with a relatively flat area of $432 \mathrm{~km}^{2}$. Its maximum elevation is just $343 \mathrm{~m}$ (BTE, 2019) above sea level, at Mount Hillaby in the parish of St. Andrew. Barbados received independence in 1966, and in 1973 became one of four (4) founding members of the Caribbean Community (CARICOM), which has since grown to fifteen (15) full members. Like most of the CARICOM states, Barbados depends heavily on the importation of fossil fuels for energy generation. This dependence on this finite resource carries with it consistent fluctuations in price due to global oil market volatility, making the island vulnerable to drastic hikes in electricity prices.

The island of Barbados is densely populated, and according to 2018 population data, the country has a population of just over 286,000 with a density of 666 persons per square kilometer (Statistics Times, 2018). According to the United Nations data, this places Barbados at no. 17 for most densely populated countries in the world, and no. 1 of the 15 CARICOM states. Due to the island's political, social and economic stability,
Barbados has a high standard of living and a very high Human Development Index (HDI) at no. 58 in the world and 2nd to the Bahamas (54) in the Caribbean (UNDP, 2018). Historically, Barbados' economy was supported by its sugar cane industry which was the island's main source of revenue. However, in more recent years, the tourism and hospitality sectors have taken over as their economic mainstay. These sectors require a great demand for energy and that demand is directly proportional to the influx of tourists to the country.

\subsection{Barbados' Energy Resources and Energy Market}

All CARICOM members are pursuing energy security. Given their dependence on fossil fuel imports, it is necessary to develop cheaper, alternative energy sources. The rate of domestic electricity is USD 0.35/kWh (Energy Chamber, 2017). The Barbados Light and Power Company Limited (BLPCL) supplies electricity to Barbados. According to the Director of Operations at BLPCL (Greaves, 2019), the energy mix at the end of 2018 is composed of:

- Fossil fuel generation plants (256 MW) at three locations--Spring Garden, Garrison and Seawell;

- PV Solar Plant (10 MW) with battery storage (5 MW) at Trent, St. Lucy; and

- Independent Power Producers (20 MW - distributed customer-owned rooftop solar PV and wind). 
Additionally, at the end of 2018, renewable energy (RE) stood at $11.3 \%$ by capacity and at $4.4 \%$ by energy produced, as seen in Figure 1. The fossil fuel generation plants consist of 6 low-speed diesel plants, 6 gas turbines, and 2 steam turbines (BLPCL, n.d.).

According to the Barbados Economic Report Energy Chapter 2017, consumption for the island was $944 \mathrm{GWh}$ for 2017 which was only an $0.04 \%$ increase from the figure for 2016. Of the energy consumed in 2017, approximately $36.2 \mathrm{GWh}$ or $3.8 \%$ of that energy came from renewable energy sources (Government of Barbados, 2018). However, according to Greaves (BLPCL) 2018 saw $0.15 \%$ drop to $942.6 \mathrm{GWh}$ in consumption for the country with $4.4 \%$ of that energy coming from RE sources. The Caribbean islands, and more so Barbados, are therefore vulnerable to the everchanging fluctuations in the price of fossil fuel-based products.

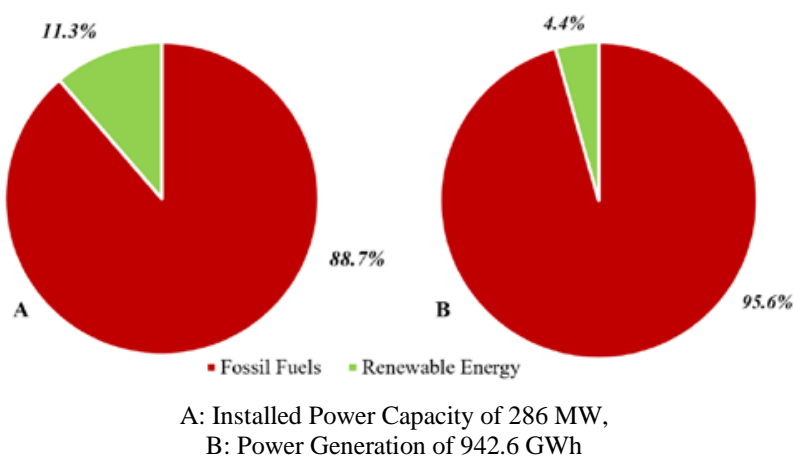

Figure 1. A 2018 Power Profile of Barbados Source: Based on Greaves (2019)

In 2013, CARICOM ratified a renewable energy policy, providing a framework for increased penetration of renewables in the region. This paper examines three distinctive annual growth rate scenarios to investigate and determine the impact of implementing 100\% renewable energy in Barbados. The investigation was informed by a myriad of technical, economic, environmental and social limitations.

\subsection{Towards an Enhanced Climate Sensitive Nation}

Increasing penetration of renewables across Barbados and a consequent reduction in fossil fuel importation is not only economically prudent but also environmentally friendly and climate-sensitive. The Caribbean has strengthened its stance at the world stage for greater reductions in greenhouse gas emissions globally. Through research published in the Intergovernmental Panel on Climate Change Special Report on the warming of $1.5^{\circ} \mathrm{C}$ above pre-industrial levels (IPCC, 2018), over 90 Caribbean and Latin American authors contributed to a body of data for increasing climate security for the vulnerable small island developing states (SIDS).
Caribbean nations over the past decade, and more recently, have been devastated by the passage of major hurricanes such as María and Irma in 2017. Barbados is among the Caribbean nations focussed on the reduction of carbon dioxide gas. The goal is to become a carbonneutral nation through the $100 \%$ transition towards renewables.

\section{Target $-\mathbf{1 0 0} \%$ Renewable by $\mathbf{2 0 3 0}$}

The Barbados Labour Party, in their 2018 Manifesto, stated that they are aiming to transition Barbados to the "first 100\% green and carbon-neutral island-state in the world” (Barbados Labour Party, 2018). The phrase "100\% green" refers to having all the electricity generation being fueled by renewable sources that are replenishable on a human timescale. This means a transition away from using fossil fuels as a source of fuel for electricity generation. Additionally, for the country to be carbon neutral, the number of carbon emissions eliminated from going $100 \%$ green will at least equal the amount emitted from other processes, namely transport (cars, sea vessels, and planes).

\section{1. $100 \%$ Renewable in Barbados}

Hohmeyer (2015) suggested that $100 \%$ RE for Barbados is both feasible and affordable. Table 1 lists the capacity for the varying source of renewable sources. Wind and solar photovoltaic (PV) at the stated capacities would supply the energy demands of the country. However, the literature discussed the importance of balancing $100 \%$ renewable energy as both wind and solar are intermittent and will not always meet the demand of the system as there is going to be large and fast fluctuations of the residual load. The difference between the power required through the demand load and the power generated results in the residual load. Thus, the residual load must be met to ensure the system is balanced and the energy supply is maintained.

Barbados requires a significant amount of storage to balance the RE sources, as Barbados has only a high potential for wind and solar. An additional alternative energy source can be obtained in the form of biomass from sugar production. Bagasse from the sugar production process is converted into a liquid biofuel that can be used to run combustion engines.

In the case of Barbados, storage must meet the maximum load of the electricity system and must at least supply that demand for 12 hours. When considering the type of storage, the storage generation capacity must be between 150 and $200 \mathrm{MW}$, with a storage volume of between 1 and $10 \mathrm{GWh}$.

Moreover, of the different types of storage technologies, pumped hydro storage was determined to be the best option. It is the only type that suits the conditions of the county and meets the required capacity while being a flexible, affordable and already mature technology. Table 1 shows the capacity for the same renewable energy 
sources to cover full electricity generation and the demand for e-mobility (i.e., the transition from petrol or diesel for transportation to electrical mobility through means of renewable energy). Hence, renewables can supply energy for electricity generation, in addition to significantly impacting the transportation sector (including power cars and buses).

Table 1. Suggested Capacities by Renewable Energy Source for $100 \%$ RE for Barbados

\begin{tabular}{|l|c|c|}
\hline Source & $\begin{array}{c}\text { Capacity for } 100 \% \\
\text { electricity generation }\end{array}$ & $\begin{array}{c}\text { Capacity for } 100 \% \mathrm{RE}+ \\
\text { demand for e-mobility }\end{array}$ \\
\hline PV & $195 \mathrm{MW}$ & $376 \mathrm{MW}$ \\
\hline Wind & $200 \mathrm{MW}$ & $452 \mathrm{MW}$ \\
\hline PHS & $1 \mathrm{GWh}$ & $3 \mathrm{GWh}$ \\
\hline Biomass & $25 \mathrm{GWh}$ & $25 \mathrm{GWh}$ \\
\hline
\end{tabular}

Source: Based on Hohmeyer (2015)

\subsection{Power Consumption}

The level of consumption for the country is impacted by population size and the number of customers. The growth of these two parameters is dependent not only on the increase in the number of individuals but also on the magnitude of energy usage per individual. Secondary to the magnitude of energy usage is how the energy is being used. This also has an impact on consumption as persons can consume far greater than is required to do tasks that could have been supplied with a lot less energy through proper Demand-Side Management (DSM). With effective DSM, the consumption can be minimised to its lowest requirement. Thus, energy efficiency is crucial to the sustainable development of the island.

\subsection{Power Production}

The production of electricity for the country is currently primarily generated from fossil fuels and therefore there must first be an increase in RE capacity to supply the demand currently supplied by fossil fuels. This increase in RE capacity must not only be in magnitude, but also by the source as each renewable source comes with its advantages and limitations. The characteristics of the different renewable energy technologies along with their sources of fuels determine the viability for their use in the Barbados energy mix. Of the different renewable energy technologies, wind, solar and biomass would be the best options for the country with pumped hydro storage for storage to cover the demand (Hohmeyer, 2015).
Energy production is not limited to just the utility power provider, Barbados Light and Power Company Limited (BLPCL). This means that private entities, both residential and business, can set up renewable energy systems and feed the power to the grid. This is facilitated by the Electric Light and Power Act 2013 and by policies such as the Government's Barbados National Energy Policy (BNEP). According to the Barbados Economic Report Energy Chapter 2017, under the Electric Light and Power Act 2013, one hundred and thirty-one (131) licences were issued to new applicants since May 2015. Of those 131 licences, 53 (40\%) were issued in 2017.

The total renewable energy capacity from those licences stood at $30 \mathrm{MW}$, of which $27 \mathrm{MW}$ were connected to the grid by the end of 2017. There were also amendments made to the Act making adjustments to the Renewable Energy Rider (RER). The RER now allows applicants to install systems up to $500 \mathrm{~kW}$ (up from 150 $\mathrm{kW}$ ): The adjustment removed the restriction that limited applicants from installing a system that produced more than 1.5 times their consumption. The report states that applicants are now applying for larger licences (Government of Barbados, 2018).

\section{Paths to 2030 Targets}

Barbados' path to $100 \%$ RE by 2030 is going to be heavily dependent on the rate of RE penetration and development per year, as well as the degree to which consumption levels can be maintained or decreased. Below are three (3) case scenarios examining the impact of varying the average energy consumption growth rate. The three cases are a base rate of $-0.055 \%$, a low rate of $0.40 \%$ and a higher rate of $3.00 \%$.

Table 2 shows the projected data for 2030 and the impact of each of the three scenarios. Each case scenario is outlined. Another factor to consider is the impact of effective DSM. The BNEP suggests a $22 \%$ reduction in consumption owing to electricity efficiency programmes and technologies (Ince, 2018). This $22 \%$ reduction was accounted for in the case scenarios by first calculating the $22 \%$ reduction total according to the 2030 figure based on the specific growth rate for the scenarios.

It then reverses calculating to determine the percentage increase each year from 2018 to reach 2030, $22 \%$ reduction value. Each case scenario's $100 \%$ RE production target is based on the growth rate set for the scenario and therefore the production targets will vary for the different cases. Figure2 shows the projected annual

Table 2. Three Case Scenarios for 100\% RE for Barbados by 2030

\begin{tabular}{|l|c|c|c|c|c|}
\hline Cases & \multicolumn{2}{|c|}{ Consumption (GWh) } & $\begin{array}{c}\text { Barrels of Oil Equivalent } \\
\text { ('000 boe) }\end{array}$ & $\begin{array}{c}\text { Cost Avoided at 100\% RE } \\
\text { (USD \$ mil) }^{\mathrm{b}}\end{array}$ & $\begin{array}{c}\mathrm{CO}_{2} \text { Emissions avoided } \\
\text { (metric tons) }^{\mathrm{c}}\end{array}$ \\
\cline { 2 - 3 } & 2019 & 2030 & 550.8 & 52.9 & 662,035 \\
\hline Scenario 1 & 942.1 & 936.4 & 528.4 & 50.7 & 635,098 \\
\hline Scenario 2 & 938.8 & 898.3 & 790.5 & 75.9 & 950,137 \\
\hline Scenario 3 & 970.9 & $1,343.9$ & & & \\
\hline
\end{tabular}

${ }^{a}$ The metric conversion of $1,700 \mathrm{kWh}$ is equal to 1 boe was utilised (Investopedia, 2019).

${ }^{\mathrm{b}}$ Cost of oil was taken at USD 96 for 2030 according to the International Energy Agency World Energy Outlook 2018 (Trends News Agency, 2018).

${ }^{\mathrm{c}} \mathrm{CO}_{2}$ Emissions was given as 7.07E-4 metric tons of $\mathrm{CO}_{2} / \mathrm{kWh}$ (USEPA, 2017). 


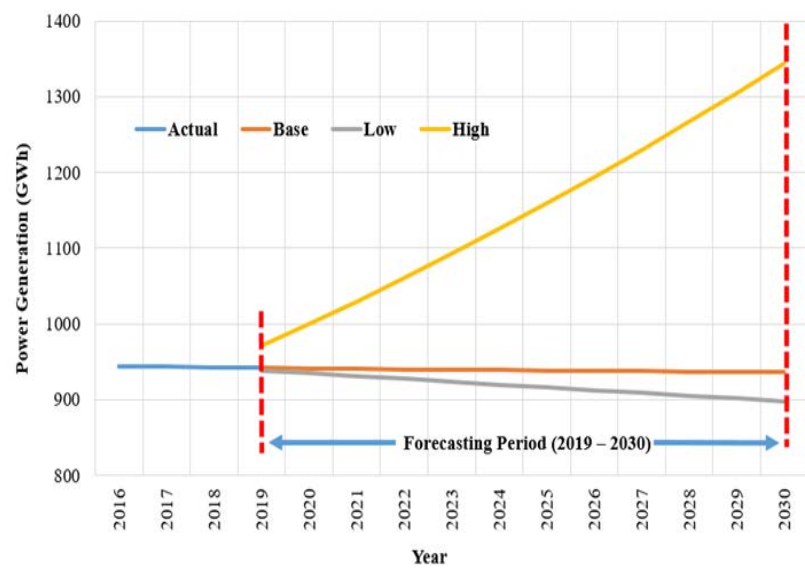

Figure 2. Forecasted System Load at Three Scenarios without DSM

energy consumption trend for the three case scenarios toward 2030.

\subsection{Three Case Scenarios}

The BLPCL's Integrated Resource Plan (IRP) indicates that the growth in electricity consumption in Barbados is strongly influenced by the country's GDP as there is a significant correlation between the two variables as observed in recent years. Therefore, the likely base case for energy consumption was determined using the forecasted base GDP growth rate of 1.6\% (BLPCL, 2012). The average annual growth rates of electricity consumption are identified for the three scenarios, as follows:

- Scenario I - Base Case: At -0.055\% - The average annual growth rate of $-0.055 \%$ for the current rate was determined from the average of the $0.04 \%$ increase in 2017 and the $-0.15 \%$ drop in 2018 . A rate of $-2.10 \%$ was determined in the scenario with DSM for a reduction of $22 \%$ in 2030 .

- Scenario 2 - Low Case: At -0.40\% - The annual growth rate of $-0.40 \%$ was used for the low case from the BLPCL IRP 2012 where they also used this rate for their low case (BLPCL, 2012). -2.44\% was used for the DSM for consumption reduction of $22 \%$ in 2030.

- Scenario 3 - High Case: At Higher Rate - An annual growth rate of $3.00 \%$ was used for the high case and, like Scenario 2, the rate came from the BLPCL's IRP. For DSM for a reduction in consumption of $22 \%$ in 2030 , an annual rate of $0.89 \%$ was used.

\subsection{Considerations towards Energy Targets}

Achieving $100 \% \mathrm{RE}$ for Barbados is going to take quite a bit of work, much of which depends on different factors. Some of the considerations that must be considered to facilitate the process include technical, economic, environmental and social aspects. Each of these is just as important to successfully reach the target.

\subsubsection{Technical and Economic Impacts}

Technical considerations in the pursuit of $100 \% \mathrm{RE}$ for a small country like Barbados include, but are not limited to, energy stability, reliability, efficiency, and diversity. Energy stability is increased as there is a greater sense of predictability of long-term energy prices as the cost of electricity will no longer be tied to the global oil market which fluctuates erratically. However, those prices will be tied to energy systems that have a greater measure of control locally. Reliability of the energy is important to consider to move away from fossil fuels, Barbados will need to be able to provide the system load from the RE sources available in the country. This lends itself to greater diversity as it is necessary for Barbados to not rely on any particular RE source but to utilise as many of the options that are both available and viable for the Barbadian context. With each of the sources, it will also be important to ensure high-quality products are used to attain the best results, as well as the most efficient and reliable system possible (Greaves, 2019).

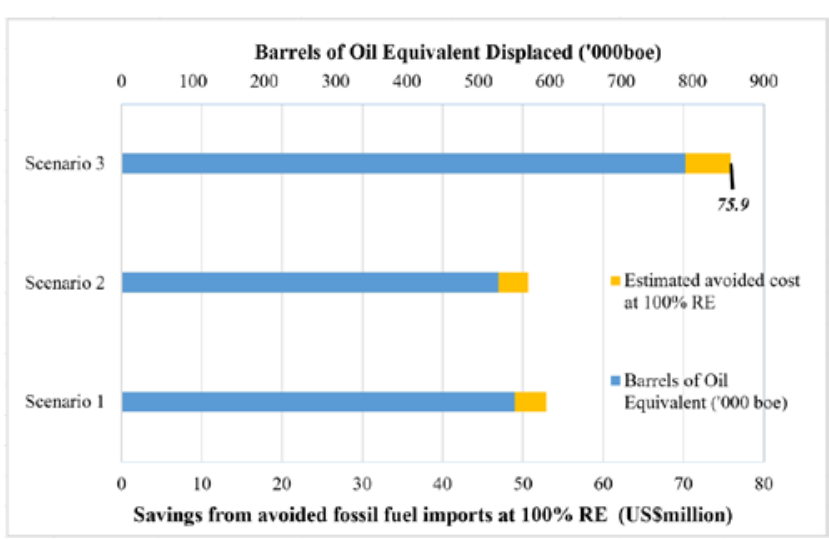

Figure 3. Projected Scenarios of Avoided Barrels of Oil Equivalent and Its Associated Savings through 100\% RE Implementation without DSM

An increase in RE capacity and energy production directly relates to a decrease in the use of fossil fuels for energy production. This allows the country to save much of its foreign exchange and the money can be spent in the local economy. A greater supply of funds in the local economy means the Government will be able to retrieve some of that money via taxation. This means that the country can both save money and earn revenue which can all be reinvested into the country's development. Scenario 3 illustrates the case of the greatest annual growth rate, and thus, through the transition to $100 \%$ renewables, will displace the greatest number of barrels of oil equivalent resulting in an avoided cost of approximately US\$ 75.9 million.

\subsubsection{Environmental and Social Impacts}


The global environment is impacted by what is done locally. Even though Barbados may be small, because of its high population density and high energy consumption, the impact of burning fossil fuels to produce the power needed to supply the country will be significant on the environment. Increasing to $100 \% \mathrm{RE}$ will significantly reduce the $\mathrm{CO}_{2}$ emissions from being released into the atmosphere.

Social considerations are vital to the development of the RE systems within the country. Time must be spent making persons aware of their role in moving Barbados to the $100 \%$ RE target, as there must be buy-in by the citizens of the country. In addition, there is the need for citizens to understand what it means for the country to be free of the bond of the global oil market and what benefits are provided because of such a shift in the source of energy.

\subsection{Research Limitations}

Research into renewable energy development in a small country, like Barbados, aiming for $100 \%$ replacement of fossil fuels by RE for electricity generation by 2030 , comes with many limitations. This paper does not consider the economic growth forecast for the country which plays a major role in determining Barbados' consumption by 2030. Any major developments in industry and manufacturing over the next decade are not factored in. Tourism is a major economic sector and brings with it a direct link to energy consumption, as growth in that sector directly increases energy demand.

Barbados is limited by space. The utilisation of land for RE technologies can therefore be challenging, with potential competition for land for other purposes. Given the make-up and location of Barbados, the country is limited to just solar PV and wind, along with biomass as sources of energy (Hohmeyer, 2015). Both solar PV and wind require significant amounts of land space for operation.

This paper does not evaluate the space requirement for these technologies and therefore utilises the specified targets identified by Hohmeyer (2015). Additionally, PV and wind are both intermittent sources and therefore not ideal for baseload supply. However, storage and biomass are proposed in the energy mix to mitigate that problem. Factors such as temperature and the weather were also not considered in this paper. Their impact on the efficiencies of the RE technologies, namely PV and wind, as well as the growing of sugar cane for bagasse to be used as a biofuel, is significant. The reserves needed for the demand calculations were not used, as the only factor considered for those calculations was the consumption from 2016, 2017 and 2018.

\subsection{Energy Efficiency Approach - Demand-Side Management (DSM)}

The three case scenarios, base, low and high, for energy consumption by 2030 indicate what the energy consumption would be like by 2030 and therefore how much energy generation is necessary to cover the demand. The base and low scenarios both have negative annual consumption growth rates of $-2.10 \%$ and $-2.44 \%$ respectively. The high scenario shows an annual growth rate of $0.89 \%$ which takes the projected consumption to 1,344 GWh in 2030. The base and low scenarios led to significantly fewer values of $936 \mathrm{GWh}$ and $898 \mathrm{GWh}$, respectively.

Renewable energy currently only accounts for $4.4 \%$ of the energy produced in Barbados (Greaves, 2019) and therefore an annual RE growth rate of $29.8 \%$ is required, beginning in 2019 , to reach $100 \%$ RE by 2030 . The $29.8 \%$ then translates to how much percentage more of the current RE needs to be installed annually as the energy produced is dependent on the capacity, as well as the technologies being used and their efficiencies. The installed capacity needed is dependent on the case scenario path the country decides to go down. Additional to the production is consumption, and this figure can be managed via DSM, which then can reduce the required demand, with scenarios 1,2 and 3 having a demand of 730.7 GWh, 700.8 GWh and 1,048.3 GWh, respectively, as shown in Table 3.

Table 3. The consumption (GWh) in 2019 and 2030 (100\% RE) with DSM Consumption Reduction of $22 \%$ in 2030

\begin{tabular}{|l|c|c|}
\hline \multirow{2}{*}{ Case } & \multicolumn{2}{|c|}{ Power Consumption (GWh) } \\
\cline { 2 - 3 } & 2019 & 2030 \\
\hline Scenario 1 w/DSM & 922.8 & 730.7 \\
\hline Scenario 2 w/DSM & 919.6 & 700.8 \\
\hline Scenario 3 w/DSM & 951.0 & $1,048.3$ \\
\hline
\end{tabular}

The DSM is very important and necessary for planning towards $100 \%$ RE supply as it will ensure the lowest possible consumption demand. This is done by introducing energy efficiency measures to minimise wastage and promote energy-saving habits. Figures 4 to 6 show the forecasted power consumption load for 2030 with and without DSM for each scenario. What about the forecasted power consumption load for Scenarios 2 and 3 ? These graphs would be useful.

\section{Conclusion}

The average annual growth rate of RE production must remain at a minimum of $29.8 \%$ for Barbados to achieve their target of $100 \% \mathrm{RE}$ by 2030, given that Barbados continues with the base rate in Scenario I without DSM. Because of the different cases, each with and without a DSM variation, what will be needed in terms of capacity will vary. Therefore, less will be required to be installed each year to remain on track.

If Barbados took the fast-tracked path with scenario III, owing to major development, a far larger RE capacity, and storage would be needed to supply the demand, which comes with a much higher capital cost for commissioning these RE systems. However, the cost and 


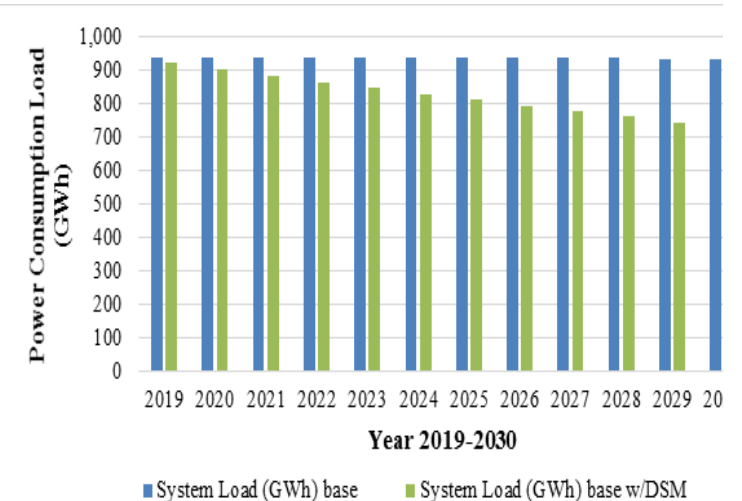

Figure 4. Forecasted Power Consumption Load for Scenario I, with and without DSM

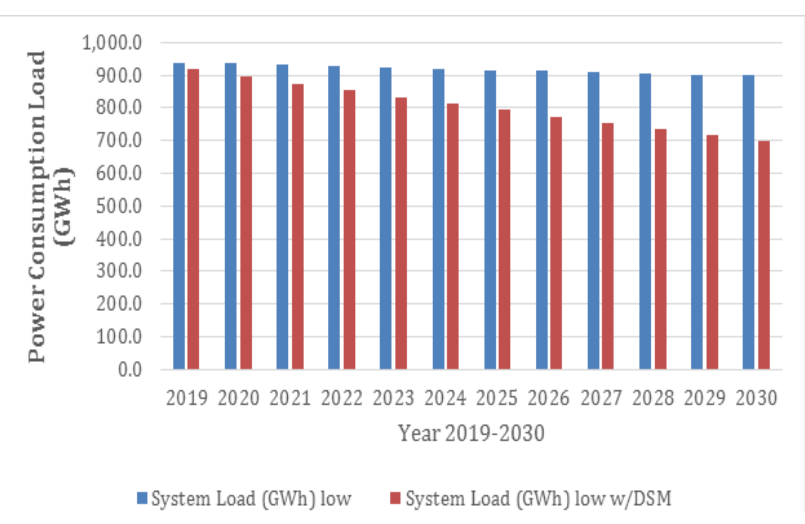

Figure 5. Forecasted Power Consumption Load for Scenario II, with and without DSM

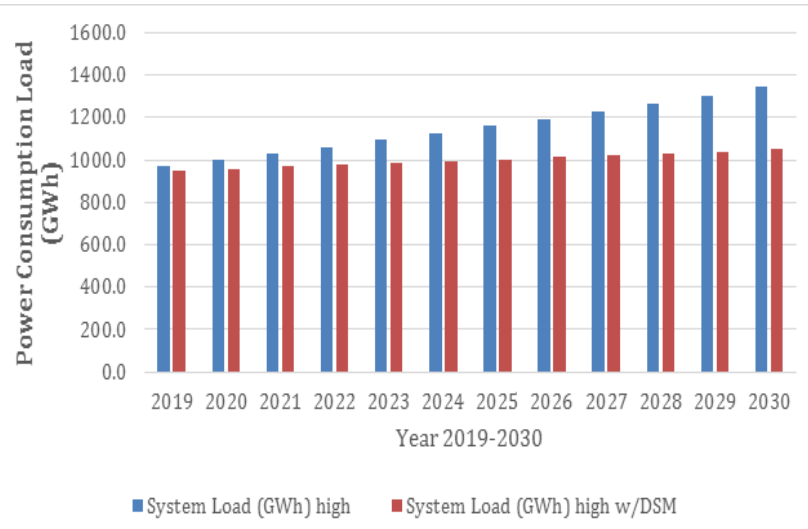

Figure 6. Forecasted Power Consumption Load for Scenario III, with and without DSM

$\mathrm{CO}_{2}$ emissions avoided will also be much greater, resulting in large savings.

A greater magnitude of annual RE capacity will be required to maintain the annual growth of RE generation needed for $100 \%$ coverage by 2030 . It is important that in planning to reach $100 \% \mathrm{RE}$ by 2030 , every effort is made by the government and the people of Barbados to manage the consumption end of the system, therefore requiring less energy to maintain a stable and reliable system for clean, affordable energy.

\section{References:}

Barbados Labour Party (2018), The People's Manifesto - Building the Best Barbados Together, Report, Bridgetown, Barbados.

BLPCP (n.d.), "How we generate electricity - Barbados”, Light and Power Company Limited, Accessed March 24, 2019. Available at: https://www.blpc.com.bb/index.php/company/how-we-serveyou/how-we-generate-electricity

BLPCP (2012), 2012 Integrated Resource Plan, Report, Barbados Light and Power Company Limited, Bridgetown, Barbados.

Investopedia (2019), "Barrels of oil equivalent”, Accessed on April 15, 2019, Available at: https://www.investopedia.com/terms/b/barrelofoilequivalent.asp.

BTE (2019), "Mount Hillaby, highest point in Barbados”, Barbados Tourism Encyclopedia, Accessed February 20, 2019.

Energy Chamber (2017), "Understanding the electricity subsidy in T\&T", Accessed on February 10, 2019. Available at https://energynow.tt/blog/understanding-the-electricity-subsidyin-tt.

Hohmeyer, Olav (2015), “A 100\% renewable Barbados and lower energy bills”, Discussion Paper, University of Flensburg, Flensburg.

IPCC (2018), “Summary for policymakers”, In: Masson-Delmotte, V., et al., (eds.), Global Warming of $1.5^{\circ} \mathrm{C}$ : An IPCC Special Report on the Impacts of Global Warming of $1.5^{\circ} \mathrm{C}$ above PreIndustrial Levels and Related Global Greenhouse Gas Emission Pathways, Intergovernmental Panel on Climate Change / World Meteorological Organisation, Geneva, Switzerland, 32 pp.

Government of Barbados (2018), Barbados Economic and Social Report 2017. Accessed April 9 2021. Available at: https://www.barbadosparliament.com/uploads/sittings/attachmen ts/3850f70a81346e8882a9bc6079633231.pdf.

Greaves, Johann (2019), Director Operations, Barbados Light and Power Company Limited, Discussion with S. Marshall, April 2019

Ince, David (2018), Barbados National Energy Policy (2017-2037), Policy Document, Government of Barbados, Bridgetown.

Ochs, A., Konold, M., Auth, K., Mosolino, E., and Killen, P. (2015), Caribbean Sustainable Energy Roadmap and Strategy (CSERMS): Baseline Report and Assessment, Worldwatch Institute, Washington, DC.

Statistics Times (2018), “Countries by population density”, Accessed February 20, 2019. Available at: http://statisticstimes.com/demographics/countries-by-populationdensity.php.

Trend News Agency (2018), "IEA improves forecast of oil price to $\$ 88$ per barrel in 2025, to \$112 in 2040”, November 132018 , Accessed March 11 2019, Available at: https://www.azernews.az/oil_and_gas/140782.html.

UNDP (2018), 2018 Statistical Update, United Nations Development Programme, Accessed February 20 2019. Available at: http://hdr.undp.org/en/2018-update.

USEPA (2017), “Greenhouse gases equivalencies calculator”, United States Environmental Protection Agency, Accessed April 15 2019, Available at https://www.epa.gov/energy/greenhousegases-equivalencies-calculator-calculations-and-references.

\section{Authors’ Biographical Notes:}

Sheldon Marshall is a postgraduate student pursuing an MSc in Renewable Energy Management with a special interest in renewable energy technologies and solutions, and building as energy systems. He is a certified Photovoltaic Associate through the North America Board of Certified Energy Practitioners, thus solidifying his keen interest in renewables. 
Randy Koon Koon is currently a lecturer in renewable energy at the Department of Physics, The University of the West Indies, Mona campus. His desire for enhanced renewable energy integration throughout the Caribbean coupled with active research in renewable technologies and energy efficiency methods positions him as an avid renewable energy advocate. 